\title{
Graduate education in Canada and China: What enrolment data tells us
}

\author{
Shumei Li: Harbin University, China \\ Tony DiPetta: Brock University,Canada \\ Mary-Louise Vanderlee: Brock University, Canada
}

\begin{abstract}
China's emergence as a global economic and political power is in part due to the country's renewed involvement with, and commitment to, graduate higher education (Harris, 2005). Graduate education in China is viewed as the means of producing the essential scientists, engineers and skilled workforce needed to sustain the country's rapid industrial growth and economic development. But how does China's graduate education system compare with North American graduate higher education and what can each learn from the other?

This paper examines the trends and patterns in Master's level graduate education programs in China and Canada based on enrolment data gathered from 1999 to 2005.

Initial comparisons of the data find that Master's level enrolments in China are growing faster than in Canada; enrolment pattern distributions for both countries are unbalanced geographically and from a disciplinary perspective the highest number of Master's level enrolments in Canada were in the business and management disciplines while in China the greatest Master's level enrolments were in engineering. The comparisons provided by this study help identify some of the trends and challenges of graduate education at both the national and the regional levels of both countries.
\end{abstract}




\section{Introduction}

Graduate higher education takes different forms from one country to the next but increasingly there are areas of commonality as well as difference (Altbach, 1991). With the current globalization of higher education, there has been a trend among countries to learn from each other in order to advance their own educational systems. China is no exception (Wu \& Zhu, 2000). This article examines Master's level enrolments in Canada and China from an international perspective and discusses the trends and challenges both nations face at national and regional levels, using comparative inquiry methodologies.

In general, comparative education has developed as a field devoted broadly to the study of education in other countries (Kelly, Altbach \& Arnove, 1982). Comparative education draws upon multiple disciplines (i.e., sociology, political science, psychology, anthropology) to examine education in developed and developing countries (Kubow \& Fossum, 2003). Comparative inquiry also encourages administrators and educators to question educational systems and the role that education plays in individual and national development (Kelly, Altbach, \& Arnove, 1982).

In this article basic factual material such as enrolment and program distribution data and changes in these data are woven into an analysis of the conditions within the two nations that define their graduate education approaches or programs. As Altbach (1991) put it: "Facts do not speak for themselves; they need to be put into a context, to be explained." The better we understand each other's strengths and differences, the better chance we have to develop more vigorous graduate education systems that can adapt to the changing realities of a global, technologically infused and increasingly competitive marketplace for higher education.

\section{Graduate Education in China: An overview}

Compared with Western countries Chinese graduate education has had a convoluted and spotted history. During the period from 1935 to 1949 for example, there were no graduate degrees conferred across China and higher education for Chinese citizens took place largely through off shore institutes in Russia and Europe (Zhou, 2004). Moreover, after the People's Republic of China was created in 1949, the government abolished the higher education degree system completely and it was not until 1978 that formal in-country graduate education was re-established (Zhou, 2004). Just over a decade later, in the early 1990's, approximately 26 provinces and municipalities in China expressed their intentions to develop higher education institutes within their jurisdictions (Yang \& Han, 2002) and less than two decades after that there are over 30 graduate institutes with degree granting powers distributed across the Chinese countryside.

Historical reviews of graduate education in China during the years of the Cultural Revolution suggest that the lack of graduate education programs and opportunities negatively effected the development of the skilled and educated people that China needed to support scientific and economic growth comparable to that in the West. It has been estimated that the lack of higher education programs set Chinese scientific and technological development back more than twenty years (Zhou, 2004). It was not until China's political leaders moved to reform education in the early 1990's that the outlook for graduate education improved and since that time enrollment in graduate programs has grown significantly (Yang, 2006). The pace of graduate education's growth in China has 
been accelerating since the turn of the century and it has been suggested that by the year 2010 China will produce as many science and engineering graduates and more PhD's than the United States (Johnson, 2000; Wang, 2004).

The modern system of higher education in China, which is barely more than a hundred years old, involves a two-fold governance structure that puts the central government in direct charge of the administration of graduate programs, and empowers the provinces, autonomous regions and municipalities with the responsibility for the local operation and the day-to- day administration of universities and colleges. In both Canada and China high level administrators such as the president or vice president are in charge of graduate education in special graduate studies departments or units. Graduate schools in both countries are relatively independent administrative units responsible for graduate education across the institution. The following section compares the enrolment figures for Master's level programs in Canada and China from 1999 through 2005 and presents findings drawn from an analysis of those data.

\section{Graduate Enrolment Patterns in Canada and China}

Figure 1 provides a graphic comparison of graduate level enrolments in Canada and China for the academic period from 1999 through 2005. It is clear in looking at the comparison that during the 5 year period in question enrolment in graduate education in China was much more explosive than enrolment growth in graduate studies in Canada.

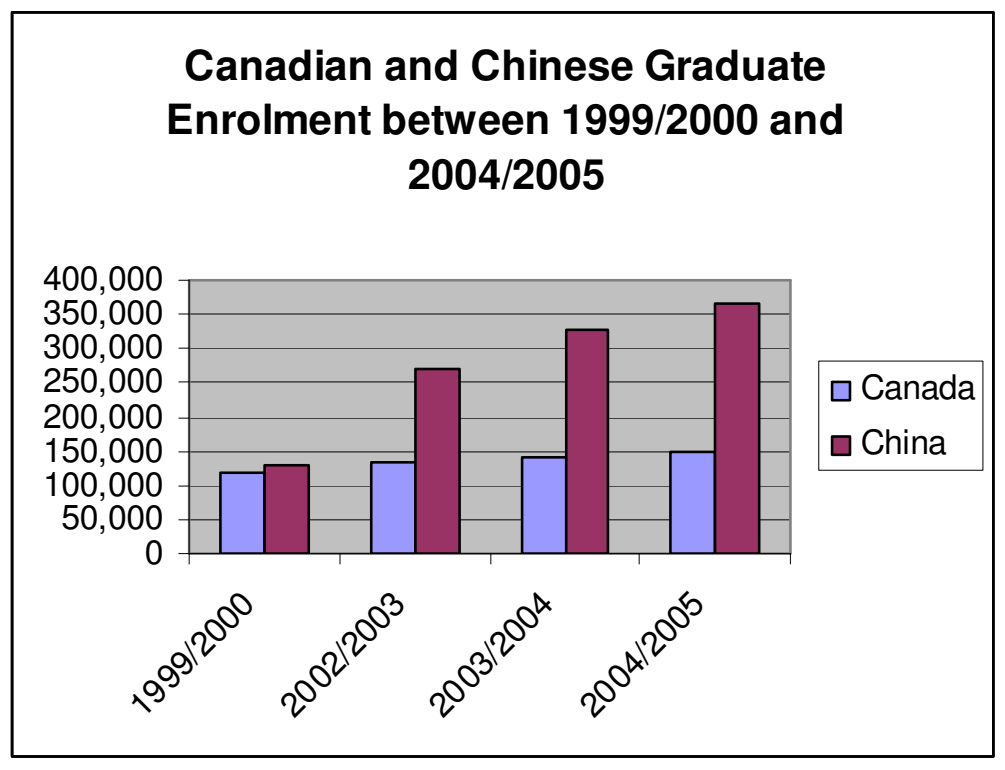

Source: Canada's National Statistical Agency (CNSA), the Daily, Tuesday, November 7, 2006 and National Statistical Bureau of China (NSBC) from 1999 to 2005: http://www.moe.edu.cn/edoas/website18/info20464.htm

Figure 1. Graduate Enrolments Canada and China: 1999 to 2005 
Expanding on the enrolment data presented in Figure 1 for 2004/2005 reveals that graduate enrolments in Canadian universities totaled 148,800 or $14.7 \%$ of the postsecondary student population (CAGS, 2006). From this total $62 \%$ or more than 90,000 students were enrolled in Master's level programs (CAGS, 2006). Master's level program enrolments in Canada have increased approximately 33\% since the early 1990's with the ratio of Master's to Doctoral degrees granted remaining relatively stable (CAGS, 2006). In comparison in the 2004/2005 academic year total enrolment in Chinese graduate education programs reached 364,800 , which represented an increase of $11.8 \%$ from the previous year and a 60.4\% increase from 1999. Enrolments in Master's level programs in Chinese colleges and universities numbered 310,000 students which accounted for $85 \%$ of the total graduate student population (NSBC, 2005).

Analyzing these enrolment data reveals that in both China and Canada, Master's level programs accounted for the lion's share of graduate student enrolment. However, while the ratio of Master's degrees to Doctoral degrees in Canada has remained relatively stable the ratio of Master's degrees to Doctoral degrees in China has increased rapidly while enrolment in Master's programs has remained relatively stable at approximately $32 \%$ of total graduate program enrolment $(\mathrm{Li}, 2006)$. These statistics indicate that while enrolment in Master's programs is increasing in both Canada and China progression from the Master's level to the Doctoral level of graduate education is not increasing at the same proportionate rate in China. There may be a variety of reasons for this but the most likely from a business and economic standpoint is that the Master's degree is the better guarantee of professional or career advancement, at least as the economy of China continues to expand and grow. This also offers a possible explanation for why the ratio of enrolment in Master's to Doctoral degree programs in Canada has remained relatively stable. Canada, as a more established industrial and resource based economy, with a longer history of higher graduate education programs aimed at business and industry professional preparation has reached a level of saturation for the kinds of professional or career opportunities that Master's level programs benefit in the national marketplace. Moreover, examining the average salary earned by graduates of Canadian and Chinese universities, the return on investment for completing a Master's degree is clear but the return on investment for a Doctoral degree is less obvious (CAGS, 2005).

The greatest increase in Master's level enrolments in China occurred during the 2000 to 2005 period, with an average annual growth of more than $14 \%$ compared to $10 \%$ for the 1996-1999 periods (He, 2003). The enrolment data for both Canada and China during this period can be used to generate trend lines that suggest that there is likely to be between a $20 \%$ to $30 \%$ increase in total university enrolment in Canada by the year 2015 (AUCC, 2000) with relatively small gains in graduate education and possibly reduced demand in some discipline areas such as education. In China meanwhile the enrolment data trend line suggests that total university enrolments will grow by $30 \%$ annually with significant growth in graduate studies (CIICN, 2004; Wong, Shen \& McGeorge, 2002). The main reason posited for the growth in graduate enrolments in both Canada and China has been the increasing market demand for retraining and professional higher education from students and employers across a variety of professional, business and arts disciplines. Moreover, in China there has been a concerted and focused political effort to improve the country's global economic competitive preparedness through higher professional education. 
Interestingly, the rapid enrolment growth in Masters' level programs in both Canada and China has had unforeseen consequences for university administrations and faculty (CAGS, 2006; Li, 2006). University administrations and faculty have had to learn to adapt and react quickly to the changing institutional environments that the increased enrolments have contributed to. Classroom, laboratory and faculty or staff office or work spaces have become severely limited and faculty and administrator recruitment and retention have become a major issue for higher education in both jurisdictions. China, moreover, faces a variety of newly realized financial or funding issues that Canada has been dealing with for over a decade and which potentially limit the rate and breadth of graduate program enrolment and expansion (CDRS, 2003). In North America some of these finance and funding issues for graduate education have been addressed through the development of a variety of business/industry, university and provincial government linkages and funding initiatives; something which China is only now starting to explore (China Today, 2004).

Along with the growth issues previously mentioned an examination of the enrolment data for graduate Master's level programs in Canada and China from the turn of the century until 2005 also highlights differences in the geographic distribution of graduate enrolments between the two countries and suggests how these distributions are reshaping the nature of graduate programs and education.

\section{Geographic Distribution of Graduate Enrolments}

The geographic distribution of graduate enrolments in most countries is largely a function of supply, demand and funding as much as it is about institutional location. Increasingly, however, as budgets grow and funding sources dwindle, institutional recruitment has become a major factor in determining where graduate students are likely to study. Recruitment for Canadian graduate programs is generally handled at the departmental level rather than through an institution-wide approach (CAUT, 2005). On a national basis every region in Canada can develop and institute individual and independent recruitment strategies depending on the number of universities in a province and other regional interests or agendas (CAGS, 2005). However, universities in two provinces, Ontario and Quebec make up approximately $70 \%$ of all enrolment in Canadian graduate programs in part because of location and reputation but also because of concerted and continuing recruitment activities for students and faculty. Non-centrally located higher education institutes such as those in the less populous areas of Northern Ontario and Northern British Columbia have had to come up with innovative recruitment and programming options in order to maintain their graduate enrolments at sustainable levels. For example a number of faculties of education associated with Northern Ontario universities have established remote campuses in the more populous southern part of the province to offer both undergraduate and graduate courses and programs in education. British Columbia is watching the progress of these southern campuses closely and considering similar options for their Northern universities (TILMA, 2006).

Figure 2 presents the geographic distribution of Master's level enrolments in Canada and China. The charts reveal that in Canada the central provinces dominate the education scene while eastern and western provincial regions account for less than a third of graduate enrolment totals. Meanwhile in China only a few prestigious universities have been granted the institutional autonomy to develop their own recruitment strategies, or to modify curriculum and programs. All other Chinese higher education institutions 
have to strictly follow the Central Policies for recruitment developed by the Ministry of Education (Yang \& Han, 2002). This protocol proscribes what universities can and cannot do in terms of recruitment, curriculum and program offerings and thereby controls both the rate of enrolment increase and the programs that can be targeted for increase.
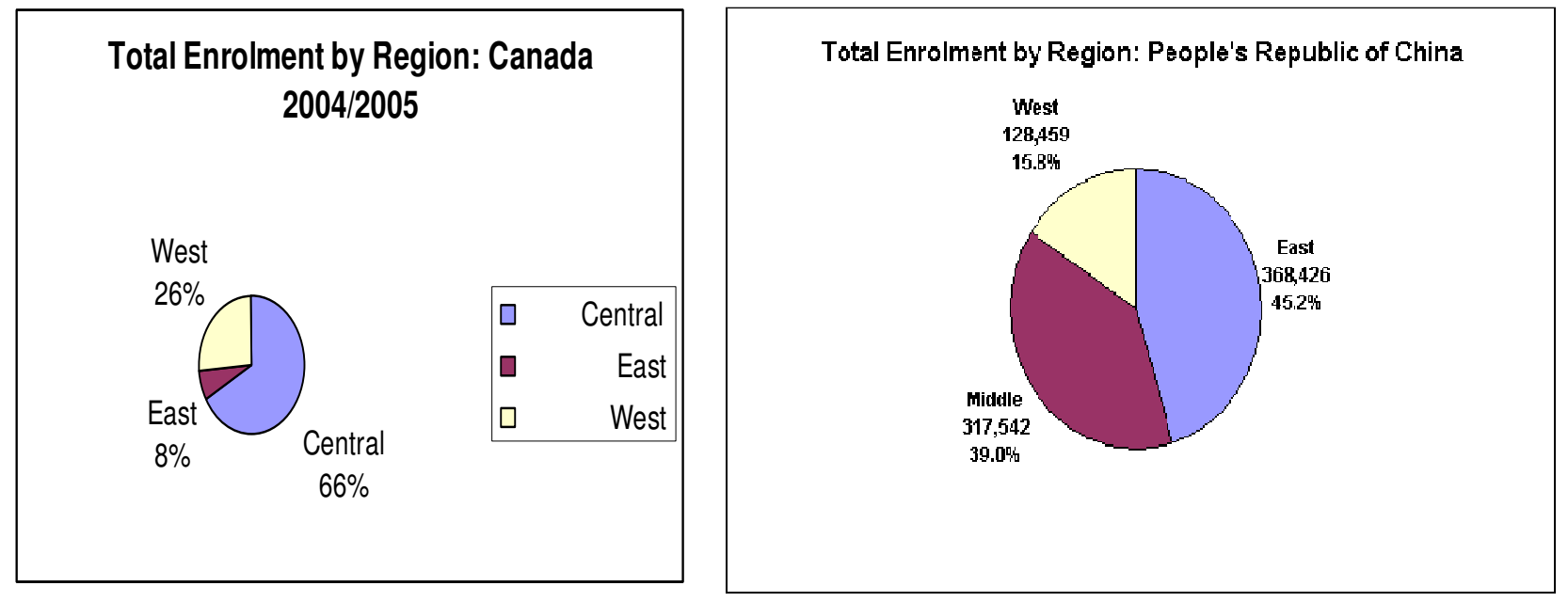

Source: National Bureau of Statistics of China (NBSC), 2005 CAUT almanac of post-secondary education 2005. Figure 2: Regional Graduate Enrolments for Canada and China

An analysis of the provincial enrolment data for Canada offers an explanation for the geographic enrolment picture presented in Figure 2. Ontario and Quebec the most populous central Canadian provinces each accounted for over one-third of Canadian Masters' level enrolments in 2004/2005, whereas British Columbia (12.3\%) and Alberta $(9.2 \%)$ accounted for approximately one-fifth of total enrolments in the same year (CAUT, 2005). Given the economic and demographic growth of these two western provinces since 2004 it is possible to speculate that enrolment rates will continue to grow as the population and the resource and energy wealth of the provinces grows. However it is important to note that the greatest growth areas for higher education still tend to be in large urban areas such as Vancouver, in British Columbia and the Greater Toronto Area (GTA) in Ontario. This urban trend may require government intervention or specialized funding in order to overcome the dominance of urban centres as graduate education centres and provide geographic representation and economic benefits to remote northern regions or less populous regional locations across the country.

Interestingly overall size, population density and economic health are not the only indicators of success in graduate program recruitment or graduation in Canada. For example while Nova Scotia, one of the smallest and poorest eastern zone provinces, accounted for only $4.2 \%$ of total graduate enrolment nationally it graduated the largest number of Master's students per capita 484 per 100,000 inhabitants in 2004/2005 (CAGS, 2006). This result distinguishes Nova Scotia from provinces comparable in economic 
development and population such as Manitoba and Prince Edward Island which have the lowest ratio of graduate students per capita in Canada (CAGS, 2006). A closer inspection of the 2004/2005 statistics reveal that only $65 \%$ of the graduates from Nova Scotia Universities are residents of that province (CAUT, 2007). Understanding how a province that is less well positioned than many others is doing so well in recruiting and supporting graduate students is something that will benefit all regional institutions. Further research is needed to define and understand the conditions and processes that have contributed to Nova Scotia's success in graduate program recruitment from other locations. Research is also needed to identify how graduate institutions and programs in smaller, less populous provinces cope with any significant number of out of province students.

The picture of China's regional graduate enrolment compared with Canada reveals some similarities and some major differences. While the urban centres of the two central provinces in Canada account for the bulk of the country's graduate education resources, in China these resources are predominantly in the urban centres of the eastern and middle provinces. However, wide variation exists between the cities of the coastal provinces, eastern cities and the middle and western provinces (Wang, 1999). Examining the enrolment data for Master's programs in China's various provinces and regions reveals that by the 2004/2005 academic year total enrolment for eastern China was 1.22 times that of the central provinces and 2.73 times the enrolment in the western provinces (CNSA, 2006). China's eastern region accounted for $45.2 \%$ of total Master's program enrolments and the central provinces accounted for $39.0 \%$ of enrolment, whereas the western regions accounted for only $15.8 \%$ of the total enrolments in Master's programs. It is noteworthy that the Canada enrolment anomalies can also be found in China. For example graduate enrolment in Xinjiang, a sparsely populated autonomous region in China's far west represents $4.9 \%$ of total Chinese graduate enrolment, a percentage higher than the total of enrolments in Qinghai province in the rich northeastern area of the country and the Ningxia autonomous region in the more culturally developed and populous central area of China (Wang, 2004).

When comparing the distribution of graduate student enrolment for Canada and China it is important to keep in mind the differences in population density and the number of universities within the two jurisdictions. Canada has a population of around 32 million but Canadian universities have a two centuries long record of providing accessible university education to students from across the country. Canada currently has 92 universities with 122 colleges distributed across ten provinces. In addition to universities and colleges, Canada's postsecondary system includes more than 400 community colleges, responding to the training needs of business, industry and the public service, as well as the educational needs of vocationally oriented secondary school graduates (AUCC, 1998; Yang, 2005). In comparison China with a population of almost 1.3 billion has 1731 universities and colleges, 872 vocational colleges and 1187 private colleges. (NBSC, 2006). The difference is size and growth rate are important considerations but they are tempered somewhat by the fact that China's history of higher education is less continuous and more idiosyncratic than Canada's.

\section{Graduate Program Trends in Canada and China}

The enrolment data for graduate programs for both Canada and China suggest an attenuation trend in terms of time to completion in graduate programs. During the 2000 to 2005 time period of this study both jurisdictions viewed reducing time to completion 
from the standard three to four years many students took as an important education sector goal. The possibility of shorter time to completion, especially in relation to professional Master's and course-based Master's programs, was something that both students and employers were interested in and advocated for, even in the "short-time" programs (CAGS, 2006; China Daily, 2006).

In response to the calls for reducing time to completion in graduate programs Canadian and Chinese institutions have tended to merge and combine some Master's programs with Master's level certificate programs and created new condensed or attenuated programs (CAUT, 2005; Liu \& Liu, 2003). Even in more traditional Master's programs departments are attempting to streamline programs so that students can graduate faster and administrators have greater control and flexibility in staffing and faculty program allocation. In some Canadian programs, the traditional thesis exit requirement is being replaced by an applied research paper or project that is shorter and more focused on practical professional issues or practices (Williams, 2005). Conversely, many programs that were originally course-based (or dissertation-based) are now offering students the option to do a thesis. Ultimately, universities hope that this will lead to the development of a research curriculum, and consequently, to new doctoral programs (CIICN, 2003).

The options available to graduate students to access higher level programs are a trending difference between Chinese and Canadian approaches to graduate education. Unlike Chinese universities, Canadian universities have been attempting to provide "indirect access" to PhD programs for students who have not formally completed a Master's degree (CAGS, 2003-2004). Many Canadian universities have implemented this informal practice in the natural sciences area. In these cases, students may transfer to a doctoral program without completing a Master's thesis, although they will have, at the very least, completed the required courses and formally presented their research interests (Williams, 2005). However, it has been noted that this kind of access is generally only available to exceptional students - those who have demonstrated great academic and research skills during the first year of their Master's program. This practice, largely confined to the natural sciences, is viewed as a means of accelerating the training, time to completion and potential contribution of exceptional students (IAOU, 2004). China has not experimented with, nor even considered indirect access for students to higher graduate education. Given the ratio of Master's to Doctoral students in China it may be something that will need to be considered in the future.

While access to a PhD program from a Master's program without completing a thesis requirement is possible in Canada, the concept of "direct access" to a $\mathrm{PhD}$ program from a Bachelor's degree program has not been well received in either Canada or China (CAGS, 2005; Li, 2006). Faculty members and university administrations appreciate the value of Master's training, as it enables them to clearly evaluate the research potential of students (Kubow \& Fossum, 2003). Moreover, Master's programs are often viewed as a form of graduate field apprenticeship and as a means of initiating graduate students into the norms and practices of their particular academic field of study (UNESCO, 2005). The trend of increasing enrolment in Master's programs, therefore, is not likely to slow in either jurisdiction.

\section{Master's programs and business and industry relations}

Another interesting difference between Canadian and Chinese Master's programs is the relationship between Master's programs and business and industry. In Canada, an 
average of 10 new Master's programs has been created by universities since the Millennium (CAGS, 2006). An important feature of many of these new programs is their flexibility in terms of completion requirements or pathways to completion. For example, in Dalhousie University's Master of Health Informatics program, students can graduate by either writing a dissertation (known as the research-oriented route) or by interning in the data management department of a medical company or related organization (known as the professionally-oriented route). In 2003/3004 one third of the program's students chose the research-oriented route while the remaining two-thirds opted to work as interns. (CAGS, 2003-2004). During the time that these new Master's programs were being created a negligible number of programs have been discontinued. Programs were discontinued for reasons such as budget cuts, retirements, low student attraction rates and the withdrawal of funding from an essential funding partner (Jones, McCarney \& Skolnik, 2005).

In 2004, the AUCC's Directory of Canadian Universities compiled information on a total of 2,699 Master's programs in 75 different universities and post-secondary institutions (AUCC, 2002b). In the same year, the National Bureau of Statistics of China reported a total of 10,989 Master's programs in 769 different universities and colleges (NSBC, 2005). The distribution of these programs across Canadian and Chinese provinces and regions is relatively consistent with the number of universities per province or region (CAGS, 2003-2004). In Canada, however, changes to existing Master's programs and the development of new programs have accelerated in response to perceived demand and calls for action from non-academic stakeholders from the business and industry sector. For example, the University of Alberta Strategic Research Plan $(2003,2006)$ notes that, the University partnered with non-university research institutions in a variety of areas including environmental research, functional foods, genomics and proteomics, information and communications technologies, and material sciences in order to provide its graduate students with the research opportunities and future jobs that they would need in the highly competitive global economy. Many of the changes affecting Master's programs in Canada stem from emerging requirements in the private and public sectors, as well as societal needs (Jones, McCarney \& Skolnik, 2002). The link between academic departments and the industrial and public sectors is stronger with respect to professionally-oriented Master's programs than it is in other program types (Albano, Fitzgerald \& Jayachandran, 1999). As a result, some programs have been created in direct response to specific demands from industry and government for specialized scientific and technological skills and knowledge (CAGS, 2006). In contrast, in China, a few provincial universities and colleges still embrace the educational model of the old planned economic system, which stressed student recruitment but neglected to consider the employment prospects for graduates of these programs. Thus, some of the programs and the curricula of universities and colleges can be viewed as distant from or irrelevant to the actual needs of society (CIICN, 2003). Programming ideas that increase the linkage of business and industry with graduate higher education such as co-operative education programs are only now starting in Chinese higher education. While the concept of the university as a separate and distant "Ivory Tower" is breaking down in North American institutions as more universities and graduate programs seek funding from and collaboration with business and industry, the concept is still quite real at many universities in China. One reason for this phenomenon is that both the Chinese economic 
system and the higher education system used to be very highly centralized. Therefore, education was provided by the central and local governments respectively and directly under their administration (PRCY, 2001). Schools lacked the flexibility and autonomy to respond in any quick or meaningful way to the changing and developing needs of the society. Since central departments and local governments were providing education separately, the structure of education was highly bureaucratized, duplicated and segmented creating a system that was slow or unable to adjust to change and one that often seemed isolated and detached from the new social and economic realities of China (Beijing Review, 2004).

\section{Discipline and Subject Area comparisons}

Enrolment data for both Canada and China show a definite and growing trend in professionally-oriented, multidisciplinary Master's programs that are terminal and course-based or of shorter-length than traditional Master's degree programs. (CAGS, 2006; China Daily, 2004). The distribution of degrees among disciplines, however, is very different between Canada and China (Wang \& Zhang, 2004). During the 2000 to 2005 academic period the highest number of degrees conferred among Canadian Master's programs, was in the business and management disciplines, which accounted for almost $30 \%$ of all Master's-level graduates. Architecture, Social and Behavioral Science, Education follow with $13.53 \%, 12.71 \%$ and $11.74 \%$ of Master's graduates respectively. It is interesting to note that enrolment in graduate programs in education declined from $17.5 \%$ of total graduate enrolments in 1994 to $11.74 \%$ of total graduate enrolments in 2004 (CAUT, 2007) suggesting as Foot (2006) has observed career opportunities in education in Canada may be on the decline with the aging of the so-called boomer generation.

While the greatest number of Master's program graduates in the 2004/2005 period for Canada came from the business and management fields the largest proportion of Chinese professionally-oriented Master's graduates (37.7\%) were from engineering programs. The next largest groups of Master's graduates in China accounting for less than half of the enrolment in graduate engineering programs were management programs with $12.6 \%$ of total enrolment, science programs with $10.2 \%$ and medical programs with 9.7\% of total Master's enrolments (NBSC, 2005). It is interesting to note that the proportion of Master's degrees associated with military programs and philosophy and history programs were in the $1 \%$ or lower range in both countries. The data on graduation rates from various disciplines may reflect the different perspectives and reactions to the growing economic and globalization focus of both countries and the desire of many students to find educational opportunities that link directly to employment or career opportunities.

Another difference in the type or character of Master's programs between Canada and China is what is happening in terms of part-time enrolments. In Canadian universities part-time enrolment in Master's programs generally has been declining since 1994.

However, education and business programs, which have a strong tradition of part-time programming, have managed to maintain their level of part-time enrolments at or above the $50 \%$ range. Further research is indicated in order to understand the practices and policies that have helped these two disciplines maintain their levels of part-time enrolment in light of the general decline in enrolments in other program areas. In comparison, enrolments in part-time Master's level programs in Chinese universities 
have been increasing since 1998 (NBSC, 2005). The increased interest in graduate parttime programs in Chinese universities is the result of a number of economic and social changes in Chinese society since the start of the century. In 2000 Chinese universities began to develop graduate programs for people who wanted to change jobs or were interested in improving their skills and abilities for job advancement in their current work. The changing economic and market conditions in China were signaling that a Bachelor's degree was no longer a guarantee of job security or promotion and that graduate degrees were becoming more important for career advancement (Fu \& $\mathrm{Chi}$, 2002). As a result enrolment in, and the development of, new graduate level programs, particularly professionally-oriented programs that offered specialized training grew significantly. Moreover, as increasing numbers of adult students began to return to universities and colleges after spending years in the workplace universities had to develop unconventional programs that fit with their new students' professional orientation and needs (Li, 2006).

\section{Emerging challenges for graduate education}

Canadian and Chinese enrolment data for the 2000 to 2005 academic period indicate that Master's level education has undergone rapid growth in enrolment and number the number of programs available to graduate students. At the same time, however Master's programs have had to cope with a tight budgetary environment and a variety of logistical problems associated with this rapid growth. Canadian and Chinese Master's level programs are thus facing a variety of challenges that paradoxically stem from their success. One of the most important trends affecting Master's programs in the two countries is the increased demand for and development professional degree programs and the design and tailoring of programs to meet the needs of the workplace. The Master's level degree is becoming the minimum standard of education for entry into many high-level professional careers in Canada. Moreover, business and industry arguments for university based research that is less academic and more focused on generating immediate social and economic benefits for the nation are increasingly being adopted by university administrations as part of their core mission statements (OECD, 2004).

The alignment of Canadian industry and university administration interests and views on graduate professional education reflects a similar alignment between Chinese government interests and university administration views that have enabled Chinese graduate programs to grow. In recent years Chinese universities have been recruiting an increasing number of graduate students into professional programs but this expansion has also caused deeper problems (He, 2003). Many universities in China have expanded graduate enrolment and incurred massive debts to fund becoming larger regardless of the potential financial risks. It seems as $\mathrm{Li}$ (2006) has noted as if expansion is equated with academic success and administrative prestige ( $\mathrm{Li}, 2006)$. Continued unabated expansion may adversely affect some of the graduate programs in China (China Daily, 2004; Beijing Review, 2004).

Another challenging trend for Canadian and Chinese universities is funding, in relation to both programs and students. In Canada, however, substantial changes in institutional funding policies and programs have been negotiated between federal, provincial and institutional interests. The federal government, which is responsible for national economic policy has strengthened the industry and economic focus of how 
university research and graduate programs are funded and provincial governments have also specifically targeted funding to graduate programs as part of their regional economic development planning (Williams, 2005). Governmental focus on Master's level programs seems to involve financial accountability, increasing the number of graduates and reducing the amount of time to completion in particular scientific and professional programs (CAGS, 2003-2004). University administrations have been quick to adapt to these governmental interests as a means of maintaining their institutional funding levels.

In China the key to solving graduate program funding issues is also seen as increased government investment. Graduate education may not be free any more in China, but the public tends to view higher education as a public welfare undertaking that should be fully funded by the government. However, given current economic circumstances worldwide expectations of full governmental funding for education appear unrealistic and so China, as Canada has been doing for over a decade, is starting to seek alternative financial channels for funding graduate education from corporate and individual investors (China Today, 2004). Moreover, as in Canada there is an increasing demand for and focus on accountability in university funding and programs which will shape the future of graduate programs in China in the near and long-term. This accountability focus is reflected in public calls for China's central government to issue preferential policies such as tax exemptions and reductions to encourage industry and individual support of university programs that will benefit both the organizations and the universities (Beijing Review, 2004). In China, the colleges and universities have begun to adjust the structure of their program areas and specialties in response to market demands and changes as well as their own needs in order to enhance their adaptability in the context of economic development. For example due to the needs for workers in specialty services in China, most institutions have added such academic programs as tourist management, hotel management, and real estate management as a way of increasing enrolment and addressing the needs of the industry (Wang, 2004).

\section{Conclusion}

Comparing the enrolment data of Master's level programs in Canada and China makes it possible to establish specific trends and patterns that are useful in understanding the particular issues and forces that graduate education in these two jurisdictions will have to deal with in the short and long term. The data from the 2000 to 2005 academic period in Canada and China reveal that while the enrolment rate for Master's programs in China is growing faster than that of Canada the conditions and issues that both countries face are similar and overlap. Both countries demonstrate unbalanced geographic distributions in Master's enrolments that seem at first glance to be the result of regional population size, density and economic prosperity but a closer examination reveals that recruitment policies and practices as well as graduate student support systems are important factors in where graduate students elect to study. Further research on these policies and practices is needed to establish how smaller institutions can maximize graduate student enrolment and retention.

The data also indicate that the highest number of Master's degrees conferred in Canada was in the business and management disciplines, while in China the highest number of Master's degrees was in the engineering field. The difference may well be a function of relative age and development of the economic systems of the two countries but there is also an element of political focus and direction involved. The Canadian 
government is positioning graduate university education as a core component of a national knowledge economy focus for global competition and growth. China on the other hand views graduate education as a means of creating the skilled labour force sector it needs to establish itself as a manufacturing and industrial global powerhouse. In both situations university administrations have been put under tight financial constraints and accountability as a means of ensuring that graduate education is aligned with national government interests and directions.

The rapid growth of Master's level enrolments must be viewed in light of the institutional and governmental focus on accountability, the tightening of funding programs and the increasing linking of graduate programs to business and industry needs and interests. It is clear that graduate education in both Canada and China is facing a number of growing pains and changes that will noticeably alter what programs are offered and the nature of how and where those programs are offered. As enrolment in Master's level programs is increasingly tied to employment rates for graduates the importance of student recruitment practices, program modification and flexibility and alternative funding systems will increase in both countries. Further research in these areas is both indicated and necessary if graduate programs are to continue to adapt to the changing economic, political and social conditions that a result of a globalized and technologically interconnected marketplace for education. Universities in both Canada and China need to find ways to promote the recognition of their Master's programs that generate national and international visibility as a way to sustain these programs in what can only be called interesting times for graduate education (AUCC, 2002a). Finally it is also important to remember that graduate education is not solely about preparing a technologically sophisticated professional class. Learning for the sake of learning as well as education to prepare future leaders, knowledge creators, and decision makers are important graduate education goals that should not be abandoned. 


\section{References}

Albano, L.D., Fitzgerald, R.W., \& Jayachandran, P. (1999). The master builder program: An integrative practice-oriented program. Journal of Progessional Issues in Engineering Education and Practice, 125(3), 112-118.

Altbach, P.G. (1991). International higher education. An encyclopedia. New York: Garland Publishing.

Association of Universities and Colleges of Canada (AUCC). (1998, August). Higher education in canada: A tradition of innovation and success, pp. 1-17. Ottawa. Annual.

Association of Universities and Colleges of Canada (AUCC). (2000, October). Opening the door to international students: An international comparison of immigration policies and practices, pp. 12-18. Ottawa. Annual.

Association of Universities and Colleges of Canada (AUCC). (2002a, April). Trends in higher education, pp. 20-28. Ottawa. Annual.

Association of Universities and Colleges of Canada (AUCC). (2002b, September). Graduate education. In: A strong foundation for innovation, pp. 8-16. Ottawa. Annual.

Beijing Review. (2004). Reform calls for follow-up actions. China international book trading corporation. Retrieved March 8, 2007, from

http://english.china.com/zh_cn/education/news/index.html

Canadian Association for Graduate Studies (CAGS). (2003-2004). The completion of graduate studies in Canadian universities: Report and recommendations, pp. 16-48. Toronto, Canada.

Canadian Association for Graduate Studies (CAGS). (2005, November). Challenges to innovation in graduate education, pp. 2-26. Toronto, Canada.

Canadian Association for Graduate Studies (CAGS). (2006, December). A profile of master's degree education in Canada, pp. 5-30. Toronto, Canada.

Canadian Association of University Teachers (CAUT). (2005). CAUT almanac of post-secondary education in Canada, 2005. Ottawa: CAUT.

Canadian Association of University Teachers (CAUT). (2007). CAUT almanac of post-secondary education in Canada, 2007. Ottawa: CAUT.

China Development Research Service (CDRS). (2003). The universities branch out. China Development Brief. Retrieved March 12, 2007, from http://www.chinadevelopmentbrief.com/taxonomy/term/2

China Daily. (2004). Higher education in china. Retrieved March 28, 2007, from http://tsearch.chinadaily.com.cn/was40/search

China Today. (2004, June). The solution. Retrieved March 26, 2007, from http://proquest.umi.com/pqdweb?RQT=318\&pmid=33494\&TS=1173723476\&clientId=1 $7280 \&$ VType $=P Q D \& V N a m e=P Q D \& V I n s t=P R O D$

China Internet Information Center News (CIICN). (2004). Colleges must learn to walk before they could run. China Daily. Retrieved March 12, 2007, from http://proquest.umi.com/pqdweb?index $=7 \&$ did=973984211\&SrchMode $=1 \&$ sid $=5 \&$ Fmt $=$ $3 \&$ Vinst $=$ PROD $\&$ Vtype $=\mathrm{PQD} \& \mathrm{RQT}=309 \&$ Vname$=\mathrm{PQD} \& \mathrm{TS}=1173721809 \&$ clientId $=1$ 7280 
China Internet Information Center News (CIICN). (2003). New moves to improve higher education. Xinhua Publishing House. Retrieved March 15, 2007, from http://www.china.org.cn/english/index.htm

Canada's National Statistical Agency (CNSA), (2006). The daily, Tuesday, November 7. Retrieved March 16, 2007, from http://www.statcan.ca/english/dai-quo/

Foot, D. K., (2006). A fortunate country: Canada in 2020. The Toronto Star, December 27, 2006. p. A25.

Fu, J., \& Chi, E. (2002). Foreign graduate education review, pp.102-133. Beijing: People Education Publishing House.

Harris, J. (2005). Emerging third world powers: China, India and Brazil. Race \& Class, 46(3), 727.

He, S. (2003). The view of expansion of Chinese graduate education. Heilongjiang Higher Education Review, 58(5), 21-28.

International Association of Universities (IAOU). (2004, May). Sharing quality higher education across borders: A statement on behalf of higher education, pp. 6-10. Institutions Worldwide.

Johnson, J.M. (2000, April). Graduate education reform in Europe, Asia and the Americas and international mobility of scientists and engineers: The proceedings of an NSF workshop. Retrieved May 1, 2007, from http://www.nsf.gov/statistics/nsf00318/

Jones, G., McCarney, P., \& Skolnik, M. (2002). Organization and administration of graduate studies in Canadian universities. The Canadian Journal of Higher Education, 24, 32-41.

Jones, G.A. (1996). Government, governance, and Canadian universities. In J.C. Smart (Ed.). Higher education: Handbook of theory and research XI, pp.337-371. New York, NY: Agathon Press.

Jones, G., McCarney, P., \& Skolnik, M. (2005). Creating knowledge, strengthening nations: The changing role of higher education. Toronto: University of Toronto Press.

Kelly, G.P., Altbach, P.G., \& Arnove, R.F. (1982). Trends in comparative education: A critical analysis. In P.G. Altbach, R.F., Arnove, \& G.P. Kelly (Eds.), Comparative Education, pp. 505-533. New York: Macmillan.

Kubow, P.K., \& Fossum, P.R. (2003). Comparative education: Exploring issues in international context. New Jersey: Merrill Prentice Hall.

Li, P. (2006). Five trends of education in the future. China Daily. Retrieved March 19, 2007, from http://english.china.com/zh_cn/education/news/

Liu, N. \& Liu, S. (2003). The structural analysis of American graduate education. World Education Information, 46(3), 46-53.

National Bureau of Statistics of China, (NBSC) 2005. Retrieved April 15, 2007, from http://www.allcountries.org/china_statistics/ 1_25_basic_statistics_on_regular_institutions.html

Organization for Economic Co-operation and Development (OECD). (2004, January). Science and innovation policy: Key challenges and opportunities. Paper presented at the Meeting of the OECD Committee for Scientific and Technological Policy at Ministerial Level. 
People's Republic of China Year-Book (PRCY). (2001). Educational restructuring deepened in overall aspects and vigorous educational system shaped. Beijing: Xinhua Publishing House.

Trade, investment and labour mobility agreement (TILMA) between Alberta \& British Columbia. (2006). Retrieved June 27, 2007, from http://www.tilma.ca/agreement/files/pdf/ABBC_MOU-TILMA_Agreement Apr06.pdf

United Nations Educational, Scientific and Cultural Organization (UNESCO). (2005). Lifelong learning and distance higher education: Commonwealth of learning, Editors: C. McIntosh \& V. Zeynep.

Wang, F. (2004). The impact of economic development on higher education in China. China \& World Economy, pp. 78-82.

Wang, X., \& Zhang, J. (2004). Foreign graduate education. Beijing: Scientific Technological Reference.

Wang, Z. (1999). Comparative review: Degree and graduate education. Beijing: Renmin University of China.

Williams, G. (2005, September). CAGS: Doctoral education in Canada: 1900- 2005. Paper presented at the conference "Forces and Forms of Changes in Doctoral Degree" for Innovation and Research in Graduate Education of the University of Washington in Seattle.

Wong, K.W., Shen, O.P., \& McGeorge, D. (2002). Development of a higher educational programme in China: The Hong Kong experience. Journal of Further and Higher Education, 26(1), 81-89.

Wu, A., \& Zhu, X. (2000). Relationship between education and economic development. Journal of Xuzhou Normal University, 26(3), 45-49.

Yang, H.Q., \& Han, Y. (2002). Introduction to comparative higher education. Beijing: People's Education.

Yang, J. (2006). The inspiration of Canadian higher education development to Chinese higher education. Henan Textile College Academic Journal, 16(2), 66-70.

Zhou, H. Y. (2004). The history of degree and graduate education. Beijing: Higher Education Press. 